\title{
THE OCCURRENCE OF LOCAL RECIDIVE IN PATIENTS WITH PLANOCELLULAR CARCINOMA OF THE LARYNX
}

\author{
Dejan Jovanovic ${ }^{1}$, Biserka Vukomanovic ${ }^{2}$, Vanja Jovanovic ${ }^{3}$ and Nemanja Rancic ${ }^{4}$ \\ ${ }^{I}$ Military Medical Academy, Institute of Radiology, Belgrade, Serbia \\ ${ }^{2}$ Military Medical Academy, Institute for Pathology, Belgrade, Serbia \\ ${ }^{3}$ Military Medical Academy, Institute of Occupational Medicine, Belgrade, Serbia \\ ${ }^{4}$ Military Medical Academy, Centre for Clinical Pharmacology, Belgrade, Serbia
}

\section{Corresponding author:}

\section{Dejan Jovanovic, MD}

Military Medical Academy, Institute of Radiology, Belgrade, Serbia

E-mail: jovanovicdrdejan@gmail.com

\section{sciendo}

UDK: 616.22-006.6-074

Eabr 2023; 24(1):33-40

DOI:10.2478/sjecr-2020-0037

\section{ABSTRACT}

Early diagnosis and adequate surgical treatment are the key factors for the course of the laryngeal cancer of the head and neck and the outcome of the surgical treatment in these patients. The aim of the paper is to compare the characteristics of the surgically treated patients with the larynx carcinoma who developed recidivism to those who did not. The study was done as a retrospective observational case-control study on a total of 90 patients with the laryngeal cancer who had been successfully operated on and whose cases had been followed over a period of at least five years after the surgery. After that, they were shorted into two groups based on the development of recidivism, and clinical characteristics of the patients with and without recidive disease were compared. 19 out of 90 patients developed recidivism. Maximum diameter of the tumour was significantly larger in patients without local recidivism. In patients without local recidivism, most common clinical stages were 3 and 4 (32.4\%, 40.8\%, respectively), whereas in patients with local recidivism stages 1 and 2 were the most common $(47.7 \%, 26.3 \%$, respectively). The average time to disease recurrence in the 19 patients who developed local recidive disease was 648.10 (384.67-911.54) days. Pathohistological analysis showed that samller the size of the tumour and lower $T$ grade at the moment of surgery are precautionary factors for further monitoring of patients with laryngeal cancer.

Keywords: Larynx, planocellular carcinoma, survival, recidivism. 


\section{INTRODUCTION}

Head and neck tumours are a heterogenous group of malignant diseases, with different clinical courses and prognoses, and their pathogenesis includes a lot of etiological factors. Planocellular carcinomas, tumours which form from the cells of covering, stratified squamous epithelium of the mucosa of the upper aerodigestive tract, account for $90 \%$ of these diseases (1). The digree of their cellular and tissual differentiation varies from well differentiated to poorly differentiated and anaplastic forms. Their biological behavior depends on the cytological and histological characteristic of the tumorous tissue. When it ocmes to localization, these tumorous include oral cavity carcinomas, all three sections of the pharynx (oropharynx, nasopharynx, hypopharynx), larynx, nasal cavity and sinuses (1-4).

Laryngeal cancer is the most common head and neck tumour (33.9\%) (1). Epidemiological studies show that middleaged and elderly men are predominantly affected. Various data point at the fact that health education, i.e. campains against smoking and alcoholism, lowers the number of addicts, and simultaneously the number of people suffering from laryngeal cancer, which underlines its importance in the prevention of the disease. Humanpapilloma virus infection (HPV) is another risk factor, which can lead to the development of carcinoma in younger population $(2,3)$. The mot common histological type of carcinoma (in 95\%) is the planocellular carcinoma (4).

Early diagnosis and adequate surgical treatment are the key factors for the course of illness in patients with planocellular carcinoma of the head and neck (5). There is ample evidence that there is a direct relationship between the presence of malignant cells in surgical margins and a higher risk for the development of recidivism (5).

The diagnosis of malignant tumour of the larynx is multidisciplinary, it lies in anamnesis, clinical otorhinolaringological examination, endoscopic examination, radiographic and pathohistological findings. Endoscopic examinations include a flexible nasopharingolaryngoscopy, endovideostroboscopy, laryngomicroscopy and aesophagoscopy. Laryngomicroscopy (LMS) is the examination of the larynx under the surgical microscope. It is done in general endotracheal anesthesia. Laryngomicroscopy is the most reliable method for the determination of the local tumour spread. In case of infiltrative tumours, there is edema, which makes tumour boundaries less clear, so they are not always easy to determin. LMS is the optimal method for obtaining tumour specimen for histological examination.

Histopathological diagnostics is the golden standard for making the diagnosis of a planocellular carcinoma. Tumours are classified based on the degree of histological and nuclear differentiation, with or without a degree of extracellular keratinization, from well to poorly differentiated degree. Today, immunohistochemical methods are very useful additional methods in pathohistological diagnostics. P16 as a surogat marker for human papillomavirus infection is of great importance for the diagnosis (6).

It is necessary that the diagnostics in case of patients with laryngeal tumour be completed with computerized tomography (CT), although the examination with nuclear magnetic resonance (NMR) is more and more common. CT does not provide sufficient data regarding very small lesions, nor regarding the spread of big tumorous lesions, but it is very useful in determining the spread of tumours to subglottis and cricoarytenoid region, to lymph nodes of the neck, and it provides insight into the surrounding bone structure. NMR can point to the early spread to cartilage and anterior commissure, as well as to submucous and transglottic spread of the tumour. NMR has the advantage over CT when it comes to determining the stage of the primary tumour, while a positive aspect of CT scan is that it lasts shorter. Meta analysis which included 63 studies, 24 retrospectives and 39 prospective cases and which was conducted in 2015, compared CT and NMR in diagnosing verification of the metastases of the neck, in case of head and neck region carcinoma, for the evaluation of the lymph node of the neck. It showed that CT has higher sensitivity, whereas NMR has higher specificity. NMR is superior when it comes to diagnosing pathological, metastatic lymph nodes of the neck, especially for confirming the diagnosis, while CT has better efficacy to exclude the metastatic lymph node (7).

The choice of the method for treatment depends on the degree of the histological diagnosis with the parameters of the spread of the illness in local structures, the invasion through blood and lymph vessels and nerves, i.e. locoregional, distant spread of the tumour, the patient's general medical condition, social conditions, and the motivation of the patient to accept the recommended way of treatment. The decision about the treatment is made for every patient individually by the Oncology consilium for malignant tumours of the head and neck region. The Oncology consilium consists of an otorhinolaryngologist, a radiation oncologist, a medical oncologist and a pathologist.

Determining the stage of the planocellular carcinoma of the head and neck influences greatly the right choice of treatment. After the processing and pathohistological verification of the planocellular carcinoma, but before the beginning of the treatment, the illness needs to be classified according to the TNM classification (TNM staging system 8-edition, 2016) by The Union for International Cancer Control (franc. Union Internationale Contre le Cancer, UICC) (8). According to this classification, small primary tumours of the head and neck, up to $2 \mathrm{~cm}$ in size (T1) and $2 \mathrm{~cm}$ to $4 \mathrm{~cm}$ (T2), are treated either surgically or with radiotherapy. The main advantage of radiotherapy is the fact that the function of the organ remains intact. In case of an advanced illness, when the tumour is more than $4 \mathrm{~cm}$ in size or there is an infiltration to the surrounding tissues (T3 and $\mathrm{T} 4$ or $\mathrm{N}+$, spread to the lymph nodes), a combined approach is necessary, i.e. surgical 
procedure, chemotherapy and radiotherapy. In case there are no clinical signs that there is spread to the lymph nodes of the neck (N0), it is nonetheless necessary to treat the neck with radiotherapy if the risk of occult metastases is greater than $20 \%$. In that case, along with the radiation of the primary tumour, elective radiation of the neck needs to be done as well (9).

In case of laryngeal cancer, radiotherapy can be used as a primary adjuvant or neoadjuvant method of treatment, most often postoperavively. Indications for postoperative radiation are: the surgery was not radical, assumption that the surgery caused the spread of the process, due to the localization of the infiltrative process, the presence of blood and lymph vessels and nerve endings, or the presence of occult regional metastases or when, upon the dissection of the neck, a lymph node whose capsule was pierced by the tumorous process was found.

The main point of postoperative radiation is the sterilization of the operating filed to eliminate possible lingering occult malignant cells, which reduces local recidivism or the possibility of the appearance of close or distant metastases. We can conclude that radiotherapy is performed postoperatively on the primary tumour location, i.e. the neck, in patients with a high risk of locoregional recidive, and this way locoregional control of the illness is improved and survival is more imminent. Postoperative radiotherapy is recommended for any $\mathrm{T}(1-4)$ carcinoma with positive $\mathrm{N}$ (nodal) status (the illness is present in lymph nodes) or if surgical margines are positive for tumorous tissue. Also, extracapsular extension of the disease (extracapsular spread of the tumour to a metastatic lymph node) is an indication for postoperative chemoradiotherapy, as well as other unfavourable risk factors such as perineural ivasion and vascular invasion, which are relative indications for postoperative radiotherapy. The addition of cisplatin during chemoradiotherapy shows a better control of the illness than radiotherapy alone in high-risk patients and in case of locally advanced illness (10). Postoperative radiation is done about six weeks after the surgery. The opinion is unanimous that during the locoregional radiation therapy treatment, the dose should be from $45 \mathrm{~Gy}$ to $50 \mathrm{~Gy}$, then, targeted RT to the affected LN (extracapsular extension of the illness) from $56 \mathrm{~Gy}$ to $60 \mathrm{~Gy}$, as well as additional radiation of the tumour bed of up to $65 \mathrm{~Gy}$, or $70 \mathrm{~Gy}(11,12)$.

Radiotherapy can be radical and palliative. Paliative radiotherapy is performed on patients who are not able to undergo other methods of specific oncological therapy and it is temporary help for the patient. In case of palliative radiation, doses are lower, $2 / 3$ of the radical dose which is delivered in hypofractionated mode. Radical radiotherapy in the head and neck region is the greatest challenge when applying conformal radiotherapy, because of a complex geometry of anatomical structures and potential complications caused by radiation. Often, the distance between the gross tumour volume (GTV) and the clinical target volume (CTV) and the organ at risk (OAT), such as the optical nerv, spinal cord or salivary gland, is not more than a few millimeters (13). Because of the potential escalation of the tumorous dose and a better locoregional control, conformal radiotherapy technique for the treatment of head and neck tumours is introduced, and its planning is based on computerized tomography - CT. At the moment, CT-NMR imaging is used in order to provide the radiation onclolgist with more precise directions for delineation, i.e. for outlining the target volumes (14). Optimal delineation of the primary tumour and involved lymphonoduses is the prerequisite for the curative radiotherapy of the planocellular carcinoma of the head and neck. When planning radiation therapy, it is important to localize the majority of peripherally embedded tumorous cells, with the aim to perform radiation of tumorous cells as precisely as possible, while sparing organs at risk. Three-dimensional conformal radiotherapy (3D RT) is a radiation technique with which the radiation dose, with its shape adjusted to the shape of the target volume, is distributed. This should enable more precise application of the therapy dose to the tumour, with minimal harm to the healthy tissue.

Figure 1. Preparatory and therapy procedures 3D CRT (conformal radiotherapy)
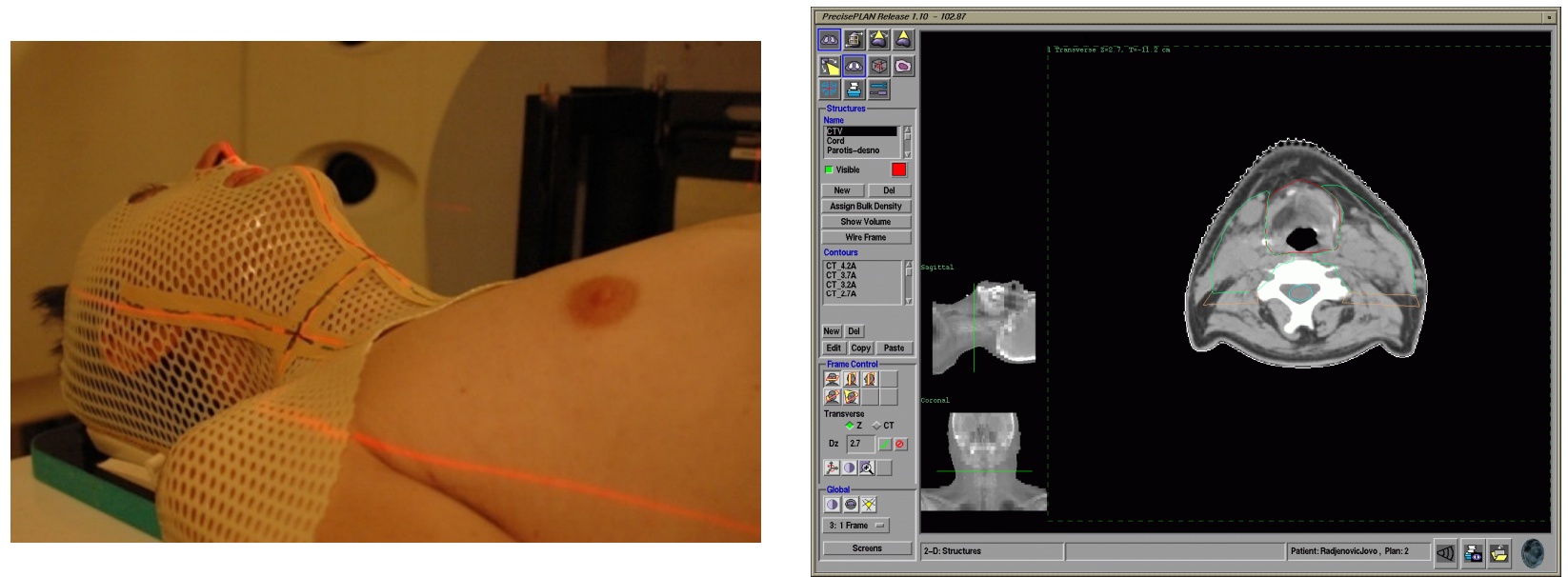
Immobilisation - making the mask and contouring volumes of interest
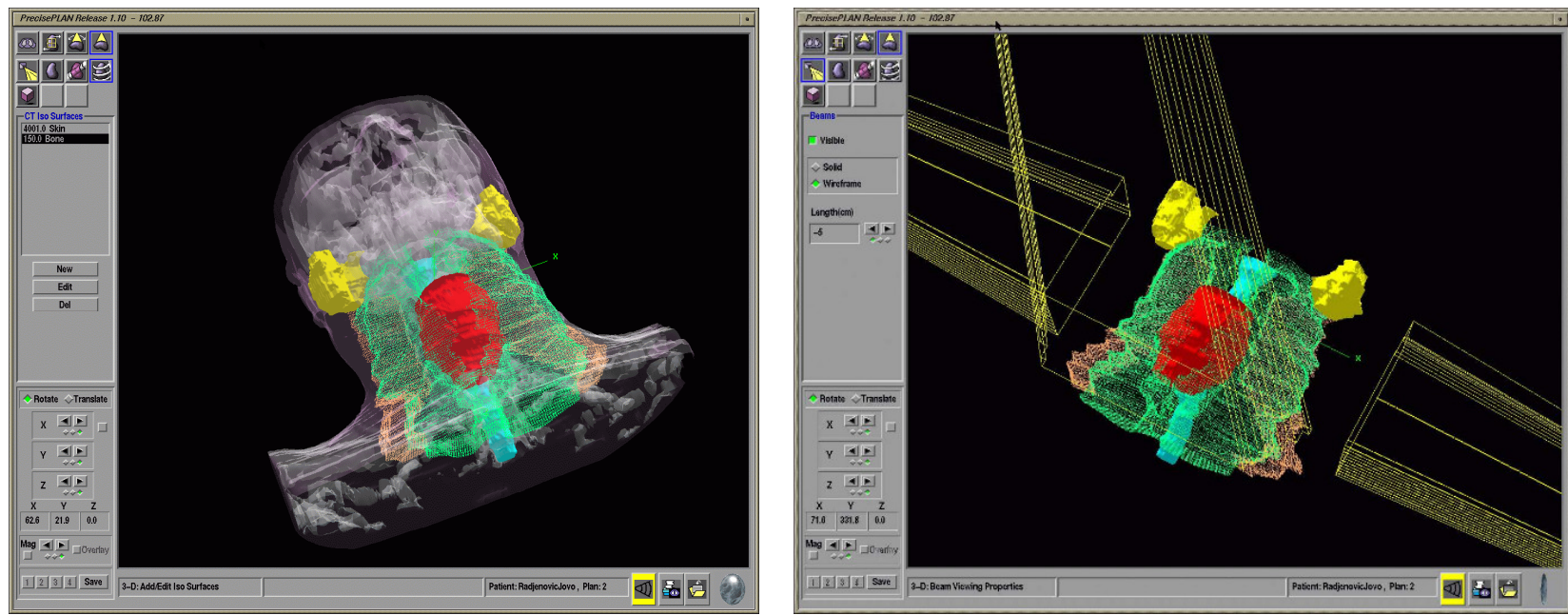

Virtual patient and beam combination

\section{METHODS}

At the Radiology Institute of Military Medical Academy, in cooperation with Otorhynolaryngology Clinic and Pathology Institute, a retrospective observational case-control study of surgically treated patients over a period of time from 2008 to 2016 and those treated with radiotherapy from 2011 to 2016 was conducted. All the patients with laryngeal cacer who received radiotherapy after the surgery were the subject of analysis. All the patiens were surgiclly treated and have postoperative radiation terapy, according to indications which it were listed in introduction. Postoperative radiation is done about six weeks after the surger in to the dose from 65 Gy to 70 Gy. They were divided into two groups: the group which developed recidive after the treatment and the group without recidive.

Sociodemographic characteristics (gender and age) and pathohistological characteristics of the tumour after surgical resection (Maximal tumours diameter, Ceratoticum, Perineural invasion, Perivascular invasion, Perilymphatic invasion, Histologic grade, Nuclear grade, $\mathrm{T}$ grade, $\mathrm{N}$ grade, Clinical TNM stage) were analysed. MSCT was also used to measure tumour diameter. Average time to recidive disease was then calculated, as well as the percentage of patients who developed recidive after one, three, five and ten years.

Complete statistical analysis was done with the statistical software package, PASW Statistics 18. Atribute variables were presented as frequency of certain categories, while statistical significance of differences was tested with the Chisquare test. Numerical variables were presented as mean with standard deviation or median with interquartile range (25-75 percentile), while statistical significance of differences was tested with the Mann-Whitney test or Independent samples $t$ test (normal or not normal distribution). All the analyses were estimated at $\mathrm{p}<0.05$ level of statistical significance.
Unadjusted time to recurrence disease or disease-free survival was calculated using Kaplan-Meier plots and p-values derived from the univariate Log-rank test.

\section{RESULTS}

The study encompassed the total of 90 patients with laryngeal cancer who were operated on and who received radiotherapy over a period of time from 2008 to 2016 at the aforementioned clinics and institutes of the Military Medical Academy. Local recidive disease appeared in 19 patients, i.e. $21.11 \%$. Statistically significat difference regarding gender and age of the patients who developed recidive and those who did not was not found (Table 1).

Table 1. Sociodemographic characteristics of the treated patients with laryngeal cancer

\begin{tabular}{|c|c|c|c|}
\cline { 2 - 4 } \multicolumn{1}{c|}{} & $\begin{array}{c}\text { Patients } \\
\text { without } \\
\text { recidive } \\
(\mathrm{n}=71)\end{array}$ & $\begin{array}{c}\text { Patients with } \\
\text { recidive } \\
(\mathrm{n}=19)\end{array}$ & $\mathrm{p}$ value \\
\hline $\begin{array}{c}\text { Gender: } \\
\text { male/ } \\
\text { female }\end{array}$ & $\begin{array}{c}58(81.7 \%) / \\
13(18.3 \%)\end{array}$ & $\begin{array}{c}17(89.5 \%) / 2 \\
(10.5 \%)\end{array}$ & $0.644^{1}$ \\
\hline $\begin{array}{c}\text { Age } \\
\text { (years); } \\
\mathrm{M} \pm \mathrm{SD}\end{array}$ & $65.45 \pm 9.60$ & $62.16 \pm 12.06$ & $0.212^{2}$ \\
\hline
\end{tabular}

$\mathrm{M} \pm \mathrm{SD}-$ mean and standard deviation;

1. Chi-square test; ${ }^{2}$ - Independent Samples t test

Table 2 shows pathohistological characteristics of the tumours after the surgical resection. There is a great difference with regart to the maximal tumour diameter, which was 
significantly bigger in patients without local recidive, compared to the patients with local recidive disease (median; 25 vs. $15 \mathrm{~mm}$ ). There is also a significant difference with regard to T stage of the disease, where the patients without local recidive were usually stage 2,3 and $4(25.4 \%, 36.6 \%, 25.4 \%$, respectively), while the ones with local recidive disease were usually stage T1 $(47.7 \%)$.
If we take a look at the clinical TNM stage, we can also see that stages 3 and 4 are the most common in patients without local recidive disease $(32.4 \%, 40.8 \%$, respectively), while in the patients with local recidive stages 1 and 2 are the most common $(47.7 \%, 26.3 \%$, respectively). In terms of other characteristics, no significant difference was discovered.

Table 2. Initially patohistological characteristics of the tumour in the treated patients with laryngeal cancer

\begin{tabular}{|l|c|c|c|}
\cline { 2 - 4 } \multicolumn{1}{l|}{} & $\begin{array}{c}\text { Patients without recidive } \\
(\mathrm{n}=71)\end{array}$ & $\begin{array}{c}\text { Patients with recidive } \\
(\mathrm{n}=19)\end{array}$ & $\mathrm{p}$ value \\
\hline $\begin{array}{l}\text { Maximal tumors diameter (according to } \\
\text { MSCT); } \\
\text { median with IQR- mm }\end{array}$ & $25.00(17.00-35.00)$ & $10.00(0.00-25.50)$ & $\mathbf{0 . 0 0 2 1}$ \\
\hline $\begin{array}{l}\text { Maximal tumors diameter; } \\
\text { median with IQR- mm }\end{array}$ & $25.00(20.00-35.00)$ & $15.00(10.00-20.00)$ & $<\mathbf{0 . 0 0 1 1}$ \\
\hline Ceratoticum: yes/no & $44(62.0 \%) / 27(38.0 \%)$ & $12(63.2 \%) / 7(36.8 \%)$ & 1.0002 \\
\hline Perineural invasion: yes/no & $14(19.7 \%) / 57(80.3 \%)$ & $2(10.5 \%) / 17(89.5 \%)$ & 0.5532 \\
\hline Perivascular invasion: yes/no & $25(35.2 \%) / 46(64.8 \%)$ & $4(21.1 \%) / 15(78.9 \%)$ & 0.3702 \\
\hline Perilymphatic invasion: yes/no & $34(47.9 \%) / 37(52.1 \%)$ & $4(21.1 \%) / 15(78.9 \%)$ & $\mathbf{0 . 0 6 5 2}$ \\
\hline Histologic grade: $1 / 2 / 3$ & $\begin{array}{c}42(59.2 \%) / 28(39.4 \%) / 1 \\
(1.4 \%)\end{array}$ & $\begin{array}{c}13(68.4 \%) / 6(31.6 \%) / 0 \\
(0.0 \%)\end{array}$ & 0.6972 \\
\hline Nuclear grade: $1 / 2 / 3$ & $\begin{array}{c}31(43.7 \%) / 38(53.5 \%) / 2 \\
(2.8 \%)\end{array}$ & $\begin{array}{c}13(68.4 \%) / 6(31.6 \%) / 0 \\
(0.0 \%)\end{array}$ & 0.1432 \\
\hline T grade: $1 / 2 / 3 / 4$ & $\begin{array}{c}9(12.7 \%) / 18(25.4 \%) / 26 \\
(36.6 \%) / 18(25.4 \%)\end{array}$ & $\begin{array}{c}9(47.7 \%) / 5(26.3 \%) / 2 \\
(10.5 \%) / 3(15.8 \%)\end{array}$ & $\mathbf{0 . 0 0 5 2}$ \\
\hline N grade: 0 / 1 / 2 & $\begin{array}{c}43(60.6 \%) / 12(16.9 \%) / 16 \\
(22.5 \%)\end{array}$ & $\begin{array}{c}15(79.0 \%) / 2(10.5 \%) / 2 \\
(10.5 \%)\end{array}$ & 0.3232 \\
\hline Clinical TNM stage: $1 / 2 / 3 / 4$ & $\begin{array}{c}7(9.9 \%) / 12(16.9 \%) / 23 \\
(32.4 \%) / 29(40.8 \%)\end{array}$ & $\begin{array}{c}9(47.7 \%) / 5(26.3 \%) / 1 \\
(5.3 \%) / 4(21.1 \%)\end{array}$ & $<\mathbf{0 . 0 0 1 2}$ \\
\hline
\end{tabular}

IQR- interquartile range (25-75 percentile);

1- Mann-Whitney test; ${ }^{2}$ - Chi-square test; MSCT- multislice computed tomography

In the 19 patients who developed recidive disease, the diameter was about 35mm (median) (table 3). Extracellular keratinisation and lymphatic invasion were present in a high percentage of cases. Their clinical stadium was usually TNM 4.

Table 3. Patohistological characteristics of recidivism in the 19 treated patients with laryngeal cancer

\begin{tabular}{|l|c|}
\hline $\begin{array}{l}\text { Maximal tumors diameter (according to MSCT); } \\
\text { median with IQR- mm }\end{array}$ & $35.00(22.75-45.25)$ \\
\hline $\begin{array}{l}\text { Maximal tumors diameter; } \\
\text { median with IQR- mm }\end{array}$ & $30.00(20.00-40.00)$ \\
\hline Ceratoticum: yes/no & $12(63.2 \%) / 7(36.8 \%)$ \\
\hline Perineural invasion: yes/no & $7(36.8 \%) / 12(63.2 \%)$ \\
\hline Perivascular invasion: yes/no & $7(36.8 \%) / 12(63.2 \%)$ \\
\hline Perilymphatic invasion: yes/no & $11(57.9 \%) / 8(42.1 \%)$ \\
\hline Histologic grade: $1 / 2 / 3$ & $1(5.3 \%) / 15(78.9 \%) / 3(15.8 \%)$ \\
\hline Nuclear grade: $0 / 1 / 2$ & $1(5.3 \%) / 12(63.2 \%) / 6(31.6 \%)$ \\
\hline T grade: $1 / 2 / 3 / 4$ & $2(10.5 \%) / 4(21.1 \%) / 5(26.3 \%) / 8(42.1 \%)$ \\
\hline N grade: $0 / 1 / 2 / 3$ & $10(52.6 \%) / 2(10.5 \%) / 5(26.4 \%) / 2(10.5 \%)$ \\
\hline M grade: $0 / 1$ & $18(94.7 \%) / 1(5.3 \%)$ \\
\hline Clinical TNM stage: $1 / 2 / 3 / 4$ & $2(10.5 \%) / 1(5.3 \%) / 5(26.3 \%) / 11(57.9 \%)$ \\
\hline
\end{tabular}

IQR- interquartile range (25-75 percentile);

MSCT- multislice computed tomography 
Time to recurrence disease was 3381.56 (3069.24- year, 5 -year and 10 -year was $93.33 \%, 82.22 \%, 81.11 \%$ and 3693.87) days on average in all the patients (Figure 3). Dis- $78.89 \%$, respectively. trubution of the patients without recidive after one-year, 3-

Figure 3. Time to recurrence of the disease in the treated patients with laryngeal cancer; means with $95 \%$ confidence interval: $3381.56(3069.24-3693.87)$ days

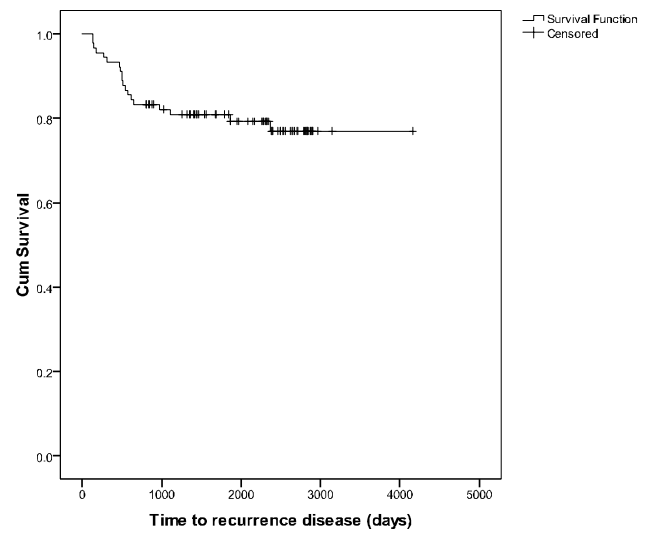

One-year, 3-year, 5-year and 10-year overall time without recidivism were $93.33,82.22,81.11$ and $78.89 \%$, respectively

On the other hand, time to recurrence of the disease in recidive disease after one-year, 3-year, 5-year and 7-year pepatients with local recidive was on average 648.10 (384.67- riod was $31.58 \%, 84.21 \%, 89.47 \%$ and $100 \%$, respectively.

911.54) days (Figure 4). The rate of the appearance of

Figure 4. Time to recurrence of the disease in the 19 treated patients with laryngeal cancer with recidive disease; means with 95\% confidence interval: 648.10 (384.67-911.54) days

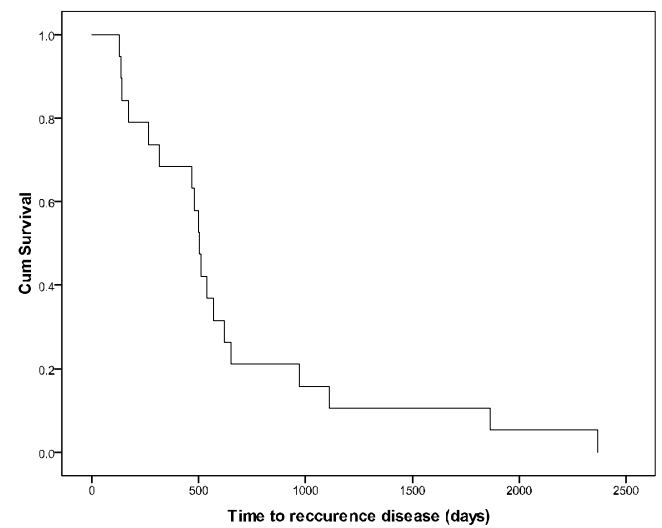

Rates of recidive in the one-year, 3-year, 5-year and 7 -year period were $31.58,84.21,89.47$ and $100 \%$, respectively

Based on logistic regression, the initial size of the tumour (maximal diameter) stands out as the only significant predictor of the appearance of the local recidive disease. In case of smaller tumours, there was 1.25 higher probability for the development of local recidive disease (Odss ratio 1.25 (1.04$1.51) ; \mathrm{p}=0.02)$.

\section{DISCUSSION}

Survival of the patients who were operated on and the absence of recidive disease are the criteria for the successful treatment of the laryngeal cancer. Any approach to treating laryngeal carcinoma leads to the development of local or locoregional recidive to a certain point. Regardless of the primary approach, regular control examinations are necessary in all stages of the disease, because recurrence of the 
locoregional disease depends chiefly on the stage of the disease (15).

In our study, which analysed a total of 90 patients with laryngeal cancer who had the surgery and recived radiotherapy and who were treated in the aforementioned clinics, local recidive disease developed in 19 patients, i.e. $21.11 \%$. The longest period of time to the development of the local recidive after the primary surgical tretament was nine years. With regard to gender distribution and age, no statistically significant difference was found between the patients who developed recidive and those who did not. Time to the development of local recidive in these 19 patients with local recidive disease was 648.10 days on average, that is about 1.77 years. One study showed that $95 \%$ of recidives appear withing the first 3.6 years (16).

Previous results shown that in $22.6 \%$ of cases out of the total number of patients, the average time within which the development of recidive was recorded was 12.6 months (17). Recidive is significantly more common in male subjects $(23.87 \%)$ than in female subjects $(12.22 \%)$. Time to recurrence of the disease is 36 months. Other authors (16) did not find the difference in the incidence of recidive between the subjects of different gender. Evaluation of the patients in various stages of the disease is what makes our studies different. Namely, their study was limited only to stage IV of the carcinoma in the glottis region, while in our study, patients with laryngeal cancer in all locations and in different stages of the disease were included and analysed, and we also did not find an important connection between gender and the development of recidive.

The initial size of the tumour (maximal diameter) was the only significant predictor of recidive that stood out in our observed group. In case of smaller tumours, probability for the development of recidive was 1.25 higher $(\mathrm{p}=0.02)$. This can be explained by the fact that in case of small tumours operated with transoral technique, specific postoperative oncological therapy is not administered. In case of locoregional spread of the tumour, chemoradiotherapy is administered postoperatively, so in this way better locoregional control over the disease is achieved, i.e. there is a smaller number of local recidive diseases. A group of authors (18) analysed 438 patients with planocellular carcinoma of the larynx, who most commonly underwent hemilaryngectomy in T2 stage, and in 76 patients $(17.35 \%)$ local recidive developed mostly during the first year so these patients received radiation therapy after the surgical treatment of the recidive disease. Another group of authors (19), in their study of 439 primarily surgically treated patients with supraglottic laryngeal carcinoma, over a period of 22 years, showed that local recidives developed in $22 \mathrm{pa}-$ tients (5\%). In case of two patients, recidive developed on the base of the tongue, in six patients on the ventricular fold and in five patients on the glottis. Total laryngectomy was performed on these patients followed by postoperative radiotherapy. Five-year survival, with no signs of illness, is $76 \%$.
A group of authors (20) describes local recidive in $12 \%$, and regional recidive in $9 \%$ of treated patients. Similarly to the previous one, another group of authors (21) examined 416 patients in stages $\mathrm{T} 1$ and $\mathrm{T} 2$, and local recidive developed in $7.2 \%$ of cases (23) The lower recidive percentage which these authors stated compared to our results can be explained by the fact that our patients with recidive disease were most often stage $\mathrm{T} 1$.

In an earlier study (18), it was shown, with regular controls after the priod of five years, that $346(79.0 \%)$ patients were without any sighns of illness and were in good general health at the moment of the examination.

A group of authors (20) stated that five-year survival of their patients after hemilaryngectomy without recidive disease was $81 \%$. Another group of authors (22) stated that in their longitudinal study of 150 patients who underwent hemilaryngectomy, two-year survival was $83 \%$. The results of the stated authors are in accordance with our findings, the distribution of patients without recidive after one-year, 3-year, 5year and 10 -year was $93.33 \%, 82.22 \%, 81.11 \%$ and $78.89 \%$, respectively.

\section{CONCLUSION}

Our study showed that the development of recidive in patients is most commonly diagnosed in stage $4 \mathrm{TNM}$. Also, in those patients, extracellular keratinisation, over $95 \%$, was present pathohistologically, as well as perilymph invasion within recidive tumour.

Moreover, the initial size of the tumour was the only significant recidive predictor which stood out in our observed group. In case of smaller tumours, probalility for recidive disease was higher. This can be explained by the fact that small tumours transorally operated do not receive specific postoperative oncological therapy. Therefore, initially diagnosed and operated small laryngeal tumours require more regular local status controls. That is to say that in case of patients who were operated using endoscopic surgical technique, regular control examinations by means of indirect laryngoscopy, with which early local recidive can be diagnosed, should be planned.

Our research points at the fact that locoregional control of the disease is very important for a successful treatment of the advanced laryngeal cancer. Only multidisciplinary approach to diagnostics and treatment of laryngeal cancer makes the survival of the patients without local recidive disease within five years from the previous treatment in over $82 \%$ of cases possible.

\section{ETHICS APPROVAL AND CONSENT TO PARTICIPATE}

The study was conducted in accordance with the ethical standards of the committee responsible for human experimentation (institutional and national) and the Helsinki Declaration of 1975, as revised in 2013. Voluntary written and 
informed consent was obtained from the patient prior to enrollment in the study

\section{CONFLICT OF INTERESTS}

The authors declare no conflicts of interest.

\section{FUNDING}

None.

\section{REFERENCES}

1. Siegel R, Ma J, Zou Z, Jemal A. Cancer statistics, 2014. CA Cancer J Clin. 2014;64(1):9-29.

2. Horn S, Ozsahin M, Lefèbvre JL, Horiot JC, Lartigau E; Association of Radiotherapy and Oncology of the Mediterranean Area (AROME). Larynx preservation: what is the standard treatment? Crit Rev Oncol Hematol. 2012; 84 Suppl 1:e97-e105.

3. Cikojević D, Glunčić I, Klančnik M. Učestalost pušenja cigareta u bolesnika s različitim oboljenjem larinksa. Med Jad. 2009;39(3-4):89-93.

4. Megwalu UC, Sikora AG. Survival Outcomes in Advanced Laryngeal Cancer. JAMA Otolaryngol Neck Surg. 2014;140(9):855-860.

5. MacKenzie RG, Franssen E, Balogh JM, Gilbert RW, Birt D, Davidson J. Comparing treatment outcomes of radiotherapy and surgery in locally advanced carcinoma of the larynx: a comparison limited to patients eligible for surgery. Int J Radiat Oncol Biol Phys. 2000; 47(1):65-71.

6. Meshman J, Wang PC, Chin R, John MS, Abemayor E, Bhuta S, et al. Prognostic significance of p16 in squamous cell carcinoma of the larynx and hypopharynx. Am J Otolaryngol. 2017;38(1):31-37.

7. Sun J, Li B, Li CJ, Li Y, Su F, Gao QH, et al. Computed tomography versus magnetic resonance imaging for diagnosing cervical lymph node metastasis of head and neck cancer: a systematic review and meta-analysis. Onco Targets Ther. 2015;8:1291-313.

8. Bertero L, Massa F, Metovic J, Zanetti R, Castellano I, Ricardi U, et al. Eighth Edition of the UICC Classification of Malignant Tumours: an overview of the changes in the pathological TNM classification criteria-What has changed and why? Virchows Arch. 2018;472(4):519531.

9. Eric KH, Rii M. Handbook of Evidence-based radiation. 2nd ed. Portland, Oregon, USA Springer; 2010.

10. Cooper JS, Pajak TF, Forastiere AA, Jacobs J, Campbell BH, Saxman SB, et al; Radiation Therapy Oncology Group 9501/Intergroup. Postoperative concurrent radiotherapy and chemotherapy for high-risk squamous-cell carcinoma of the head and neck. N Engl J Med. 2004; 350(19):1937-44.

11. Bentzen SM, Constine LS, Deasy JO, Eisbruch A, Jackson A, Marks LB, Tet al. Quantitative Analyses of Normal Tissue Effects in the Clinic (QUANTEC): an introduction to the scientific issues. Int $\mathrm{J}$ Radiat Oncol Biol Phys. 2010;76(3 Suppl):S3-9.

12. Gill A, Givi B, Moore MG. AHNS Series - Do you know your guidelines?: Assessment and management of malnutrition in patients with head and neck cancer: Review of the NCCN Clinical Practice Guidelines In Oncology (NCCN Guidelines). Head Neck. 2019;41(3):577-583.

13. Eric K.H., Rii M. Handbook of Evidence-based radiation. 2nd ed. Portland, Oregon, USA Springer; 2010.

14. Vandecaveye V, De Keyzer F, Nuyts S, Deraedt K, Dirix P, Hamaekers P, et al. Detection of head and neck squamous cell carcinoma with diffusion weighted MRI after (chemo) radiotherapy: correlation between radiologic and histopathologic findings. Int J Radiat Oncol Biol Phys. 2007;67(4):960-71.

15. Ferlito A, Haigentz M Jr, Bradley PJ, Suárez C, Strojan P, Wolf GT, et al. Causes of death of patients with laryngeal cancer. Eur Arch Otorhinolaryngol. 2014 Mar; 271(3):425-34.

16. Spector GJ, Sessions DG, Lenox J, Newland D, Simpson J, Haughey BH. Management of stage IV glottic carcinoma: therapeutic outcomes. Laryngoscope. 2004;114(8):1438-46.

17. Markou K, Christoforidou A, Karasmanis I, Tsiropoulos G, Triaridis S, Constantinidis I, et al. Laryngeal cancer: epidemiological data from Northern Greece and review of the literature. Hippokratia. 2013;17(4):313-8.

18. Milovanović J, Djordjević V, Trivić A, Baljošević I, Milovauović A, Petrović Ž et al. Rezultati hemilaringektomije u primarnom hirurškom lečenju carcinoma larinksa. Acta chirurgica Iugoslavica. 2004;51(1):27-29.

19. Petrović Ž, Djordjević V, Nešić V. Hirurška terapija supraglotisnog karcinoma larinksa. Med Pregl. 2008;61(56):242-246.

20. Scola B, Fernández-Vega M, Martinez T, Scola E, Fernández-Vega S, Ramírez C. The Gregorio Marañón Hospital experience with vertical partial laryngectomies. Eur Arch Otorhinolaryngol. 1999;256(6):296-8.

21. Laccourreye O, Weinstein G, Brasnu D, Trotoux J, Laccourreye H. Vertical partial laryngectomy: a critical analysis of local recurrence. Ann Otol Rhinol Laryngol. 1991;100(1):68-71.

22. Maceri DR, Lampe HB, Makielski KH, Passamani PP, Krause CJ. Conservation laryngeal surgery. A critical analysis. Arch Otolaryngol. 1985;111(6):361-5. 